\title{
Capturing the Frames of News Story Leads in Philippine Dailies: A Discourse Analysis
}

\author{
Emily T. Astrero ${ }^{1 *}$, Joel M. Torres ${ }^{2}$ \\ $1 \& 2$ Department of Secondary Education, College of Education, Central Luzon State University, Philippines
}

\begin{abstract}
\begin{tabular}{llllll}
\hline Received: 05.11.2020 & • Accepted: 20.12.2020 & • & Published: 31.12.2020 & • Final Version: 31.12 .2020
\end{tabular}
Abstract: Using 31 news leads found in news articles published in Philippines newspapers - three broadsheets and one tabloid - the present study describes the news leads' organizational structure and identifies the shared cultural context evoked by the news leads. The analysis of the news discourse employed Bhatia's (1993) genre analysis focusing on communicative purpose, and Simpson's (2000) physical structure analysis. The study revealed that the genre of journalism, specifically in the 31 news leads, fulfilled its main communicative purpose - which is to convey information - through direct, summary, or conventional lead. The leads are characterized by brevity and directness, with adherence to the ideal length consisting of 35-word limit in both broadsheet newspapers and tabloid newspaper. The result implied that writing pattern or written discourse is influenced by the culture of specific genre, in this paper, the genre of journalism. The result manifested that Filipinos are capable of adaptation to rules in a particular genre. The study served as an avenue in finding out the conclusion that digressiveness, which is a characteristic of writings of Oriental writers, is not always evident in the discourse of newspaper compositions of Filipino writers. This study may be helpful to researchers who wish to analyze culture through discourse analysis using a specific genre.
\end{abstract}

Keywords: discourse analysis, academic colloquium, semantic macrostructure, schematic, superstructure

\section{INTRODUCTION}

Genre analysis has always been a multi-disciplinary activity attracting attention not only from linguists, discourse analysts, communication experts and rhetoricians, but also from sociologists, cognitive scientists, translators, advertisers, and plain English campaigners (Bhatia, 2002). It may be seen as a reflection of the complex realities of the world of institutionalized communication, further defined either as regularities of staged, goal oriented social processes (Martin, 1993), as consistency of communicative purposes (Swales, 1990), and as the study of situated linguistic behavior (Bhatia, 1993). Interestingly, journalism is one of the disciplines that linguists and rhetoricians have explored and analysed through genre analysis.

The genre of journalism is a phenomenon regarded as a vital part of everyone's daily routine. It is channeled to the audience through a discourse, either broadcast or printed form. The printed media, specifically the newspaper, is published primarily to inform the reader through the news stories. The information people get from these news stories serve as guide, inspiration, warning, or just a mere update of an action or a pursuit. Tamara (2002) and Estrada, and Nem Singh (1987) claim that news is anything that interests the reader, tomorrow's history of today, or literature in a hurry, and still added that it is a timely factual report of events, ideas, or situations interesting or significant to the public. Similarly, news, according to Ramirez (1989), Pangilinan (1975), and Mencher (2010) - is a record of the most interesting, important, and accurate information obtained about the things man thinks and says, sees and describes, plans and does. With these various definitions, it is safe to say that NEWS is an abbreviation of what is happening in the North, in the East, in the West, and in the South. 
Every news story in a newspaper has a beginning paragraph which is called the lead. Since newspapers are read rapidly, the opening of the story requires the most attention from the reader and the writer. On the assumption that readers may not finish reading the article, the writer must worry about the lead and not the conclusion, and therefore must stuff the lead with the big features, and must consider the length. The lead must be organized in such a way that it catches attention and understood by the hurried reader. News stories in Philippine newspapers employ different ways in the construction of lead paragraphs.

Ramirez (1989), Estrada and Singh (1987), Pangilinan (1975), Tamara (2002) define lead as a special beginning paragraph of a news story. It provides quick identification of persons, places, events, necessary for quick understanding of the story, and therefore the most important part of the story. With so many sources of information - newspapers, magazines, TV, radio and the Internet - audience simply are not willing to read beyond the first paragraph (and even sentence) of a story unless it grabs their interest. A good lead does just that. It gives readers the most important information in a clear, concise and interesting manner.

News leads, like headlines, reach an audience considerably wider than those who read the articles, since all those who buy the paper will glance, if only fleetingly, at the headlines then search for the lead for the basic and most vital information. Lead comes after headline, and together they precede the rest of the news item. Their structural function is also clear. Together, they express the major topics of the text. That is, they function as an initial summary. The semantic constraint is obvious: Headline+Lead summarise the news text and express the semantic macrostructure. Obviously, some newspaper headlines and lead paragraphs do provide what seems to be a summary (or abstract) of their stories. Some leads are presented with a single detail extracted out of the story, and others contain a quotation which the editor decided should be promoted to the foreground. The fact that leads do not always summarise, but sometimes highlight or quote, has been noted by different writers. Bell (1991), for example, makes a distinction between leads which summarize the story's main event, and leads which underscore secondary details or events. The impact news leads on the reader is likely to be all the stronger because certain linguistic features of titles make them particularly memorable and effective: impact is deliberately sought through the use of 1) summary, direct, or conventional lead, and 2) story, creative, delayed, or non-conventional lead with emotive vocabulary and other rhetorical devices.

Several studies in the genre of journalism have been conducted by various researchers. These areas include newspaper headlines (i.e., Lombardi, 2018; Ulum, 2016; Dor, 2003; Ifantidou, 2009; Bucaria, 2004; Kronrod \& Engel, 2001; Dayag, 2010), and editorials such as the works of Dayag (2004), Pulido (2011), Mashror (2013). However, a discourse analysis specific of sub-genre investigating the kinds of lead paragraphs in news articles seem to be desolated and created a gap, considering that the lead is the most important part of a news story (Estrada \& Singh, 1987; Pangilinan, 1975; Ramirez, 1989) and practically “tells it all”. Since life is a race of fast activities, journalism must keep with the pace. The basic questions what, when, where, who, why, and how, must be answered in a swift, thus, news must have a strong opening story. With so many sources of information newspapers, magazines, TV, radio and the Internet - audiences simply are not willing to read beyond the first paragraph (and even sentence) of a story unless it grabs their interest. A good lead does just that. It gives readers the most important information in a clear, concise and interesting manner.

In this paper, the genre of journalism as a specific discourse community is investigated. Primarily aimed to inform, it employs specific disciplinary practices, procedures, and cultures understood in the community of news reporting and news reading. Filipino journalists are assumed to be bounded by the rules on the development of lead in the news story. Given the numerous ways on how to write the lead in relation to the various types of lead, the writer, with the readers in mind, practically develops his or her article. Hence, this study attempts to investigate gap in the literature as regards to the organisation of news leads focusing on the length of the paragraph as determined by the number of words, and to identify the type of news lead that dominates the construction of news articles published in leading Philippine newspapers. This study discloses the impact of specific genre to the writing patterns 
employed in news writing through description and identification of structural patterns of news leads in news stories.

\section{Methodology}

\subsection{Corpus of the Study}

The three broadsheet newspapers, namely Manila Bulletin (MB), Philippine Daily Inquirer (PDI), and Philippine Star (PS) are among the country's top broadsheets in terms of readership as borne out by surveys conducted in 1995 by Networks Marketing Consulting Group, an independent American firm, and in 1999, by Asia Research Organisation (ARO), an affiliate of Gallup International (Dayag, 2002). The other newspaper, a tabloid-Tempo, was chosen since it is the only tabloid newspaper published in English but is different from broadsheets in terms of set of target readers (Pangilinan, 1975). The three broadsheets were Manila Bulletin, Philippine Daily Inquirer and The Philippine Star, and a tabloid-Tempo. These newspapers are all Philippine newspapers published in English in national circulation.

The corpus of the study (Table 1) consisted of 31 news leads from four newspapers gathered for four consecutive days (i.e., July 25-28, 2016) 100 days after President Rodrigo Roa Duterte assumed office. Two news stories for each of the four newspapers each day were chosen. The news stories covering the same subjects (i.e., expectations on the Philippine President's State of the Nation Address; signing of the Freedom of Information Bill) that appeared on all the newspapers were the subjects.

Table 1. Corpus of the Study

\begin{tabular}{lll}
\hline Newspaper & Classification & Date of Publication \\
\hline Manila Bulletin (MB) & Broadsheet & July 25-28, 2016 \\
Philipine Daily Inquirer & Broadsheet & July 25-28, 2016 \\
The Philipine Star & Broadsheet & July 25-28, 2016 \\
Tempo & Tempo & July 25-28, 2016 \\
\hline
\end{tabular}

\subsection{Analysis}

Genre is primarily characterised by the communicative purpose it intends to fulfill (Bhatia, 1993). In this study, lead paragraphs were analyzsed using two considerations-the Physical Analysis by Simpson (2000) and Bhatia's (1993) Genre Analysis, which focused on communicative purpose.

The analysis was operationalised by a description of the physical structure or the Physical Analysis by Simpson (2000) where the physical characteristics of the paragraphs were analyzed using simple counts of the number of words, number of sentences, number of words per sentence, number of clauses, and number of clauses per sentence. The concept on physical structure analysis was adapted since length is an important consideration in lead paragraph. If a lead is too long, it will not be informative or interesting (Develotte \& Rechniewski, 1999). The number of words employed along with the $5 \mathrm{Ws}$ and $\mathrm{H}$ reveals a specific type of lead.

While this paper did not work exactly as Bhatia's (1993) genre analysis, this was primed on the premise that the main purpose of lead paragraph in news story fulfills a communicative purpose which is to inform via a particular strategy. Further viewed as communicative event characterized by a set of communicative purpose situated in institutionalized setting (such as journalism), it identifies a linguistic pattern identified and mutually understood by members of the professional or academic community in which these news regularly occur.

The physical structures of lead paragraphs fulfill certain purposes and reflections about disciplinary and organizational cultures. Hence, the types of leads such as summary/direct/conventional and story/creative/delayed/non-conventional fulfill a specific journalistic purpose that reveals a cultural representation of Filipino culture thru Philippine journalism. As Hinkel (1994) claimed," written texts represent a convergence of different stylistic, cultural, religious, ethical, and social notions" (p. 353).

Table 2 shows the various presentations of news on the topic what to expect about SONA. Out of four lead paragraphs, three employed summary/direct/conventional lead with only one 
story/creative//delayed/non-conventional. L1 and L4 start with the 'what' angle, signaling that the most important aspect for the writer's viewpoint is the "what theme" in the news. It is interesting to note that same author write lead story in two sister newspapers-MB and Tempo. L2 foregrounds the 'who'angle, conveying that the most important in the story is the person, while L3 attacked the lead by employing a delayed "what" angle, which is considered non-conventional. L1, L3, L4 adhere to the ideal 35-word, while L2 exceeds by two, but still maybe considered insignificant increase from the ideal length.

Table 2. Sample news article on the topic, "What to expect about SONA?" (July 25, 2016)

\begin{tabular}{|c|c|c|c|c|}
\hline $\begin{array}{l}\text { Newspa } \\
\text { per }\end{array}$ & News Lead & Author & $\begin{array}{l}\text { Num } \\
\text { ber of } \\
\text { words }\end{array}$ & Type of Lead \\
\hline $\begin{array}{l}\mathrm{MB} \\
(\mathrm{L} 1)\end{array}$ & $\begin{array}{l}\text { Love of country will be the central theme } \\
\text { of the first State of the Nation Address } \\
\text { (SONA) of President Duterte today amid his } \\
\text { administration's intensified efforts to combat } \\
\text { illegal drugs, crime, and corruption. }\end{array}$ & Kabiling, G. & 33 & al Summary/Direct/Convention \\
\hline $\begin{array}{l}\text { PDI } \\
(\mathrm{L} 2)\end{array}$ & $\begin{array}{l}\text { President Duterte is expected to outline a } \\
\text { road map for his six years in office in what is } \\
\text { touted to be a stiring } 38 \text {-minute address today } \\
\text { that his aide said would "awaken the patriot in } \\
\text { every Filipino". }\end{array}$ & & 37 & $\begin{array}{l}\text { Summary/Direct/Convention } \\
\text { al }\end{array}$ \\
\hline $\begin{array}{l}\text { TPS } \\
(\mathrm{L} 3)\end{array}$ & $\begin{array}{l}\text { It's a } 38 \text {-minute address written by the } \\
\text { President himself, and he expects the speech } \\
\text { to stir the patriotism of every Filipino. }\end{array}$ & Romer, A. & 21 & $\begin{array}{l}\text { Story/Creative/Delayed/Non } \\
\text {-Conventional Lead }\end{array}$ \\
\hline $\begin{array}{l}\text { Tempo } \\
\text { (L4) }\end{array}$ & $\begin{array}{l}\text { Love of country will be the central theme } \\
\text { of the first State-of-the-Nation-Address of } \\
\text { Preseident Duterte today amid his } \\
\text { administration's intensified efforts to combat } \\
\text { drugs, crime, and corruption in the country. }\end{array}$ & Kabiling, G. & 33 & $\begin{array}{l}\text { Summary/Direct/Convention } \\
\text { al }\end{array}$ \\
\hline
\end{tabular}

$\mathrm{L}=$ lead

\section{Results and Discussion}

\subsection{Length of the News Leads}

Shown in Table 3 is the summary for the length of leads of news articles in all the 31 news leads in both broadsheet and tabloid newspapers. Length of leads comprising of words below 35 are most common at a frequency of 21 or $67.74 \%$. Only 10 news leads employed 36 words or more $(32.26 \%)$ in writing the lead paragraph.

Paragraph leads on the topic what to expect from the SONA of President Duterte and the signing of Freedom of Information Bill were presented in various ways. It is interesting to note that two news leads have the same lead paragraph, written by the same correspondent. These news leads are:

Love of country will be the central theme of the first State of the Nation Address (SONA) of President Duterte today amid his administration's intensified efforts to combat illegal drugs, crime, and corruption in the country.

This may be attributed to the fact that Manila Bulletin and Tempo are sister newspapers. It is evident that the number of words per lead paragraph does not vary significantly, except for another lead with five words, since it is a non-conventional lead (i.e., The long wait is over) classified under story/creative/non-conventional lead. Mencher (2010) stated that in news reporting, the lead paragraph 
should not exceed the ideal 30-35 word-limit, followed by the leads exhibited in the table, exceeding a not significant number, still acceptable within the word-limit requirement.

Table 3. Length of News Leads

\begin{tabular}{|c|c|c|c|}
\hline & $\begin{array}{l}\text { Length of News Leads } \\
\text { (number of words) }\end{array}$ & $\mathrm{f}$ & $\%$ \\
\hline 35 and below & & $1^{2}$ & $67.74 \%$ \\
\hline 36 and above & & $0^{1}$ & $32.26 \%$ \\
\hline Total & & $1^{3}$ & $100 \%$ \\
\hline
\end{tabular}

Table 4 validates the result of length of news leads in conformity to types of lead. Summary/direct/conventional lead adheres to 30-35-word limit for a lead paragraph, while story/creative/delayed/non-conventional lead employs 36 words and more. Therefore, the type of lead most frequently used as shown in Table 4 is summary/direct/conventional lead (23 or $74.19 \%$ ) compared to the story/creative/delayed/non-conventional lead ( 8 or $25.81 \%$ ).

Table 4. Types of News Leads

\begin{tabular}{|c|c|c|}
\hline Types of News Leads & $\mathrm{f}$ & $\%$ \\
\hline $\begin{array}{l}\text { Summary/Direct/ } \\
\text { Conventional Lead }\end{array}$ & $3^{2}$ & 74.19 \\
\hline $\begin{array}{l}\text { Story/Creative/ } \\
\text { Delayed/Non-conventional Lead }\end{array}$ & 8 & 25.81 \\
\hline Total & $1^{3}$ & 100 \\
\hline
\end{tabular}

Table 5 reveals the type of paragraph leads used in broadsheet and tabloid newspapers. Results show that both newspapers employed conventional news leads such as summary/direct/ at $80 \%$ and $83.33 \%$. A small percentage, $20 \%$ and $16.67 \%$, recorded lead paragraphs that employed non-conventional news lead such as story/creative, for broadsheet and tabloid, respectively.

Table 5. Types of News Leads in Broadsheet and Tabloid Newspapers

\begin{tabular}{|c|c|c|c|c|}
\hline Newspaper Type & $\begin{array}{l}\text { Summary/Direct/Conventional Lead } \\
\text { (Frequency) }\end{array}$ & $\%$ & $\begin{array}{l}\text { Story/ Creative/ Delayed/ } \\
\text { Non-conventional Lead } \\
\text { (Frequency) }\end{array}$ & $\%$ \\
\hline Broadsheet (25) & 20 & $\begin{array}{r}80.0 \\
0 \%\end{array}$ & 5 & $20 \%$ \\
\hline Tabloid (6) & 5 & $\begin{array}{r}83.3 \\
3 \%\end{array}$ & 1 & $\begin{array}{r}16.6 \\
7 \%\end{array}$ \\
\hline
\end{tabular}


Out of four lead paragraphs for the news article "what to expect about SONA", three employed the conventional lead and only one made use of non-conventional. Two of the lead paragraphs started with the "What" angle of conventional lead, signaling that the most important aspect for the writer's viewpoint was the "what theme" in the news, while another lead with the "Who" angle, conveying that the most important in the story was the person. The Five W's and H- who, what, when, where, why, how - are most important.

The signing of Freedom of Information Bill was the second topic in all the newspapers. Interestingly, the news article was told mostly in non-conventional lead, with the use of adjectives "long" (wait) "landmark" (order), and "historic" order which do not conform to the characteristics prescribed for a good story lead since adjectives employ opinion and are regarded as not objective (Ramirez, 1987; Pangilinan, 1975). Only Tempo (Lead8) employed the Summary/Direct taking the "Who "angle using the recipient "the public" rather than the doer.

Contrary to the topic Freedom of Information Bill, which was told in three non-conventional lead paragraphs, the news topic "highlights of SONA" employed three conventional leads. In the newspapers, three lead paragraphs, the "who" angle in the Direct story fashion was employed, conveying that the newspapers view President Duterte as the most important element in the lead paragraph, while one lead attacked the news lead in the "what" angle. Tempo Lead12 used the nonconventional lead. The total number of words in each lead adhered to the 35-limit word requirement for a news lead. Moreover, summary lead was used in all lead paragraphs in all the newspapers, leaving Tempo which did not publish the topic "Senate President". This may be attributed to the fact that the senate presidency was treated under the news on SONA, and therefore was no longer discussed as a separate news item. In terms of total number of words, it is worth mentioning that one lead employed 83 words in four sentences.

The 17th Congress formally opened yesterday and two prominent lawmakers from Mindanao-Senator Aquilino Pimentel III and Davao del Norte Rep. Pantaleon Alvarez-formally taking the helm as Senate President and House Speaker respectively to push the legislative agenda the Détente administration. Twenty of the 24-member Senate voted for Pimentel of Cagayan de Oro as the 22nd Senate President. His father, Aquilino Q. Pimentel Jr. was the Senate's 18th president. Both are bar topnochers. He is the first son to repeat his father's achievement. (Casayuran, M. \& B. Rosario)

This is unusual for a lead paragraph which is expected to meet the 35-word limit to make the information precise and brief. In order to meet the length requirement, unnecessary words or phrases, and unintentional redundancy must be watched out. Avoid clutter and cut right to the heart of the story. The unconventionality of this lead paragraph clearly shows the digressive culture of Filipinos even in news story telling, supposed to be bounded by journalistic rules. One lead made use of Conventional lead using data of statistics as strategy answering one of the five basic questions Who, What, Where, Why, and an $\mathrm{H}$ to stand for how many. (With 20 votes from his peers, Senator Aquilino Pimentel III is now the Senate President. (Sy, M.)

Meanwhile, two selected news stories were present in all the four newspapers. The first news story was on "Peace Talk". Three leads employed summary lead while one employed non-conventional lead. It can be noted that three lead paragraphs fielded words ranging from 28 to 31 , with adherence to the 35-word limit. On the other hand, 52 words were used to state the same news in one lead. Moreover, the four leads vary in the opening clauses exhibiting different angles of beginning. MBLead17

Peace talks between the government and Muslim rebel groups, TPS19A unilateral ceasefire with communist rebels was declared yesterday by President Duterte, TempoLead20 Armed Forces of the Philippines Chief of Staff Gen. Ricardo Visaya has ordered the suspension of military operations against the Communist Party. 
It is worthy to mention the words "peace talk", "ceasefire" and "suspension of operations" since they have synonymous meanings. This places lexis as the core of a language (Lewis, 1993).

The topic "TRO on Curfew" was written using summary lead in newspapers MB, TPS, and Tempo while PDI crafted the lead paragraph using non-conventional lead, also exhibiting the longest lead with 37 words.

In what appears to be the first major setback in President Duterte's war on criminality, the Supreme Court yesterday issued a temporary restraining order (TRO) on a 10 p.m. to 5 a.m. curfew clamped in Manila, Quezon City, and Navotas.

PDI successfully delayed the topic by using a grammatical beginning clause. MB, (The Quezon City government) TPS and Tempo (The Supreme Court) used the Who opening in their summary leads.

Conventional lead introduced the first topic "Ph-China dispute on sea". Words employed range from 19 to 37, considered as within the 35-word limit.While the three broadsheets capitalise on using Philippine-China in the news lead, signalling an international issue with the presence of US in the picture, the tabloid Tempo in one lead paragraph presented the same news topic focusing on intranational aspect by limiting the news on the First Family.

In the topic "Cyclist shot to death" only TPSLead31 attacked the lead using the shortest number of words-11, and creatively constructed the news lead in Story/creative/delayed/nonconventional approach. Armed and extremely dangerous, this man is wanted, "dead or alive. All other newspapers broke the news using summary/direct/conventional approach with number of words ranging from 19-25. Interestingly is the presence of adverb "extremely" and adjectives "armed" and "dangerous" which do not adhere to the no-adjective in the lead paragraph rule if taken from the viewpoint of the writer that beginning writers make the mistake of overusing adverbs and adjectives in their leads. Concentrate instead on using strong verbs and nouns.

Further, the use of "shoot to kill" and "dead or alive", "looking for" and "accused" are some lexical words that are employed in the story to mean the same thing. This supports Swales (1990) in his claim that lexis and genres work in communicative furtherance.

\section{Conclusion}

Results strengthens the relationship between language and culture, which are intricately related to each other to a certain extent that they are somehow inseparable (Cedar \& Setiadi, 2016 in Torres, Balasa, Ricohermoso \& Alieto, 2020; Torres \& Medriano, 2020; Torres, 2020). This study found that the average length of lead paragraphs both in broadsheets and tabloid adhere to the 35-word limit, which means that lead paragraphs in Philippine newspapers follow the rules in terms of word limit when writing the news leads, resulting to the predominant type of lead paragraph in both broadsheets and tabloid is conventional lead. This type of lead is characterized by brevity and directness, which is a shared culture in the field of journalism, as opposed to the non-linear characteristic of Oriental writers, where Filipino journalists belong. This implies that the shared culture in journalism, which include brevity and directness imply, that Filipinos are capable of adaptation to rules in a particular genre. This concludes that digressiveness, which is a characteristic of writings of Oriental writers, is not always evident in the genre of newspaper compositions of Filipino writers and writing pattern is influenced by the culture of a specific genre. Hence, it points out the adaptability and resilience of Filipinos.

Therefore, it can be inferred that journalists adhere to the 35-word limit rule on lead paragraphs when writing news stories. This supports the claim of Pangilinan (1975) that brevity and length are attributive to understanding and retention of information. Summary/Direct/Conventional Lead is also predominant in Philippine newspapers validated in the $74.19 \%$ usage. Results fulfill Bhatia's (1993) genre analysis focusing on communicative purpose operationalized by a description of the physical 
structure specifically the length of the paragraph through the number of words employed. In his definition (inspired by Swales, 1990 ) genre is "primarily characterized by the communicative purpose(s) it is intended to fulfil" (p.209)

The communicative purpose of the lead paragraph is to inform. While this paper did not work exactly as Bhatia's genre analysis, the fulfilment of the communicative purpose of the genre, which is to inform, was realised via a particular strategy called types of leads and physical structure specifically the length of the lead paragraph. Predominant use of Conventional Lead is reflected in both broadsheet and tabloid. It can be inferred further that the genre of journalism has a distinct process and distinct lexis in the fulfilment of communication process, and this is the culture of journalism.

To establish the fluidity or solidity of the structure of the genre of journalism in the Philippines, the study is suggested to be done every ten years, since the validity of data is ten years. This may unveil the innovativeness of writers in a genre, and may be regarded as a medium in analyzing if the culture of a specific society or nation is revealed in the genre.

\section{REFERENCES}

Bhatia, V. (2002). Applied genre analysis: a multi-perspective model. City University of Hong Kong: Hong Kong.

Bhatia, V. (1997). On Vijay K. Bhatia: Analysing Genre: Language Use in Professional Settings . Hermes Journal of Linguistics, 19, 207-239. Retrieved from: https://pure.au.dk/portal/files/10013/H19 20.pdf

Bhatia, V. K., (1993). Analysing Genre -Language Use in Professional Settings. London:

Longman, Applied Linguistics and Language Study Series.

Bell, A. (1991). The Language of News Media. Blackwell, Oxford.

Bucaria, C. ( 2004). Lexical and syntactic ambiguity as a source of humor: The case of newspaper healines. International Journal of Humor Research, 17(3), 279-309.

Cedar, P. \& Setiadi, A. (2016). Performance of Indonesian EFL learners and Thai EFL learners in compliment responses in English. International Journal of Applied Linguistics and English Literature, 5(7), 63-76.

Connor, U. (1996). Contrastive Rhetoric. Cambridge University Press.

Dayag, D. (2004). Editorializing in L2: The case of Philippine English. Asia Pacific Education Review 5,100-109. https://doi.org/10.1007/BF03026283.

Develotte C. \& Rechniewski, C. (2001). Discourse analysis of newspaper headlines: a methodological framework for research into national representations. Web Journal of French Media Studies, 4 (1), 1-16.

Dor, D. (2003). On Newspaper headlines as relevance optimizers. Journal of Pragmatics, 35(5), 695721.

Estrada, E. \& Singh, R. (1987). Basic Journalism. Manila: National Bookstore.

Hinkel, E. (1994). Native and nonnative speakers' pragmatic interpretations of English texts. TESOL Quarterly, 28(2), 353-376. 
Ifantidou, E. (2009). Newspaper headlines and relevance: Ad hoc concepts in ad hoc context. Journal of Pragmatics, 41(4), 699-720. Retrieved from:

https://www.sciencedirect.com/science/article/abs/pii/S0378216608002798

Kingery, D. \& R Furuta. (1997). Information Processing \& Management. Elsevier.

Kronrod, A. \& Engel, O. (2001). Accessibility and referring expressions in newspaper headlines. Journal of Pragmatics, 33(5), 683-699.

Lombardi, D. (2018). Critical Discourse Analysis of online News Headlines: A Case of the Stoneman Douglas High School Shooting. https://pdfs.semanticscholar.org/8e91/10d3c08bc4fd86705c9b9c96f5591edc4fb8.pdf

Martin, J. R. (1993): A Contextual Theory of Language. In The Powers of Literacy -- A Genre Approach to Teaching Writing. Pittsburgh: University of Pittsburgh Press. Retrieved from: https://eric.ed.gov/?id=ED367980

Masroor, F. (2013). Argumentative Strategies of Newspaper Editorials in English across Cultures. The Asian ESP Journal Summer Edition, 9(3), 35-72. Retrieved from: http://asian-espjournal.com/wp-content/uploads/2016/01/AESP-Volume-9-Issue-3-December-2013.pdf

Mencher, M. ( 2010) News Reporting and Writing. columbia.edu

Nir, Raphael (1993). A discourse analysis of news headlines. Hebrew Linguistics, 37, 23-31

Pangilinan. E. (1975). Journalism Handbook. National Bookstore

Pulido, D.H. ( 2011). A systemic functional analysis of Philippine English newspaper editorials. TESOL Journal, 4(1), 52-63. Retrieved from: http://www.tesol-journal.com https://tesolinternational-journal.com/wp-content/uploads/2013/11/V4_A4.pdf

Ramirez, J. (1989). Philippine Journalism Handbook (3 $3^{\text {rd }}$ edition). Manila:National Bookstore.

Simpson, J. M. (2000). Topical structure analysis of academic paragraphs in English and Spanish. Journal of Second Language Writing, 9(3), 293-309.

Swales, J. M. (1990): Genre Analysis - English in Academic and Research Settings. Cambridge: Cambridge University Press.

Tamara, B. (2002) American Journalism: History, Principles, Practices. In W. David Sloan and Lisa Mullikin Parcell (Eds.). Journalism. Jefferson, NC: McFarland \& Company, Inc., American. Retrieved from: 10.1080/08821127.2002.10677878. https://www.tandfonline.com/doi/abs/10.1080/08821127.2002.10677878

Torres, J.M. (2020). Politeness strategies vis-à-vis genders and exposures to western culture: The case of

the 'The Voice of the Philippines' coaches. International Journal of Linguistics and Translation Studies, 1(3), 100-117.

Torres, J.M. \& Medriano, R. (2020). Rhetorical Organization of Ilocano and Tagalog Pre-service teachers in their argumentative essays. The Asian EFL Journal, 27(2.2.), 261-286.

Torres, J.M., Balasa, K.A., Ricohermoso, C., \& Alieto, E.O. (2020). Complimenting strategies in sociolinguistic settings: The case of Ilocano and Tagalog pre-service teachers. The Asian ESP Journal, 16(5.1), 202-253.

Ulum, Ö. ( 2016). Newspaper Ideology: A Critical Discourse Analysis Of News Headlines On Syrian Refugees In Published Newspapers. Turkish Studies, 11(15), 541-552. 
46 Astrero \& Torres.: Capturing the Frames of News Story Leads in Philippine Dailies: A Discourse Analysis 